\title{
Response of Some Soybean Cultivars to Low Light Intensity under Different Intercropping Patterns with Maize
}

\author{
Tamer Ibrahim Abdel-Wahab ${ }^{1}$, Rehab Ahmed Abd El-Rahman ${ }^{2}$ \\ ${ }^{1}$ Crop Intensification Research Department, Field Crops Research Institute, Agricultural Research Center, Giza, Egypt \\ ${ }^{2}$ Food Legumes Research Department, Field Crops Research Institute, Agricultural Research Center, Giza, Egypt
}

Email address:

twins00twins50@yahoo.com (T. I. Abdel-Wahab)

\section{To cite this article:}

Tamer Ibrahim Abdel-Wahab, Rehab Ahmed Abd El-Rahman. Response of Some Soybean Cultivars to Low Light Intensity under Different Intercropping Patterns with Maize. International Journal of Applied Agricultural Sciences. Vol. 2, No. 2, 2016 pp. 21-31.

doi: $10.11648 /$ j.ijaas.20160202.11

Received: February 15, 2016; Accepted: March 11, 2016; Published: April 14, 2016

\begin{abstract}
A two-year study was carried out at Mallawi Agricultural Experiments and Research Station, A.R.C., El-Minia governorate, Egypt, during 2014 and 2015 seasons to determine the compatible soybean cultivar with high maize plant density to achieve farmer's benefit under intercropping conditions. Alternating ridges $(70 \mathrm{~cm}$ width) between maize and soybean were used as 1:3, 2:4, 2:2, 3:3 and 4:2, respectively, in addition to sole culture of both crops. Local maize cultivar T.W.C. 310 was grown in one plant per hill distanced at $30 \mathrm{~cm}$ under intercropping and sole cultures, meanwhile local soybean cultivars (Giza 22, Giza 82 and Giza 111) were drilled in both sides of the ridge (two plants/hill distanced at $15 \mathrm{~cm}$ ) under intercropping and sole cultures. A split plot distribution in randomized complete block design with three replications was used. The results indicated that maize yield attributes were increased significantly by decreasing maize plant density from 67 to $25 \%$ of sole maize under intercropping conditions, meanwhile the converse was true for plant height and grain yield per ha. All the studied maize traits were not affected by soybean cultivars. Also, all the studied maize traits were not affected the interaction between intercropping patterns and soybean cultivars. Soybean yield and its attributes were increased significantly by decreasing maize plant density from 67 to $25 \%$ of sole maize under intercropping conditions except plant height. The late-maturing soybean cultivar Giza 22 recorded the highest values of intercepted light intensity within soybean canopy, number of pods per plant, seed index, seed yields per plant and per ha, meanwhile, the highest values of biological yield per ha, plant height and number of branches per plant were recorded for soybean cultivar Giza 111. Soybean cultivar Giza 22 gave the highest seed yield per plant compared to the other cultivars under all the intercropping patterns. Relative yield of soybean showed that the earlymaturing soybean cultivar Giza 82 is better adapted to low light intensity than the other cultivars. Land equivalent ratio and area time equivalent ratio values for intercrops were greater than 1.00 indicating less land requirements of intercropping patterns than sole maize. Growing four maize ridges alternating with two ridges of soybean cultivar Giza 82 achieved the highest net return compared to sole maize.
\end{abstract}

Keywords: Intercropping Patterns, Maize, Soybean Cultivars, Low Light Intensity, Net Return

\section{Introduction}

In Egypt, there is the need to expand the scope of soybean [Glycine max. (L.) Merr.] cultivation through intercropping system. Egyptian farmer suffering from increased costs of soybean production when planted and eventually gets a lower net returns as compared with the other strategic summer crops such as maize (Zea mays L.) where demand for the maize grains in the Egyptian market is intensively increasing.
Maize cultivated area reached about 814435 ha in 2013 with an average yield of 7.64 ton per ha, meanwhile, the soybean acreage reached about 9270 ha in 2013 with an average yield of 3.61 ton per ha [1].

Over the past few decades, increasing attention has been given to intercropping in Egypt. Several studies have reported that maize - soybean intercropping is more productive than the individual sole crops [2, 3, 4, 5 and 6].

In general, maize yield was not affected by the presence of soybean while soybean yield was reduced specially under 
high maize population [7]. Adjusting planting density is an important tool to optimize crop growth and the time required for canopy closure, and to achieve maximum biomass and grain yield [8]. Recently, the practice of intercropping soybean with maize is common, particularly amongst smallholder farmers who have to optimize their use of limited land. Generally, intercropping legumes with cereals is usually done to maximize productivity in many parts of the Mediterranean region [9].

However, crop species in intercropping pattern must be carefully chosen to minimize competition and enhance the efficient use of water, light and nutrients [10]. Success of intercropping pattern depends on the ability of the second crop to become established under the canopy of the first crop in variable midsummer conditions. Intercropping of incompatible species can result in one crop completely suffocating the other; that is adverse effects [11]. It is known that the light plays an important role in the vegetative development of soybeans. There are two types of plant response to light, firstly' the plant responds to the duration of the light period and this response is called the photoperiodic response. Secondly, plants respond to the intensity of the light source. Seed yield of soybean reduced under the low light because of reduction in dry matter production [12]. To obtain the maximum seed yield of intercropped soybean under shading effects of adjacent maize plants, selection of suitable soybean cultivar could play an important role for intercropping system. The cultivars may respond to shading stress differently in terms of growth and yield. Seed yield of soybean consists of several components, including the number of plants per unit area, pods number per plant, seeds per pod, and seed size [13]. Therefore, the main objective of the present research was to determine the compatible soybean cultivar with high maize plant density to achieve farmer's benefit under intercropping conditions.

\section{Material and Methods}

A research was carried out at Mallawi Agricultural Experiments and Research Station, El-Minia governorate (31 ${ }^{\circ} 06^{\prime} 42^{\prime \prime} \mathrm{N}, 30^{\circ} 56^{\prime} 45^{\prime \prime}$ E, $17 \mathrm{~m}$ a.s.1.), Egypt, during 2014 and 2015 seasons. Wheat was the preceding winter crop in both seasons. The experimental soil texture was clay. Table (1) shows pedigree, flower color, leaf shape, country of origin and maturity of the tested soybean cultivars.

Table 1. Pedigree, flower color, leaf shape and country of origin of the three soybean cultivars.

\begin{tabular}{llllll}
\hline Soybean cultivar & Pedigree & Flower color & Leaf shape & Country of origin & Maturity \\
\hline Giza 22 & Giza $21 \times 186 \mathrm{k}-73$ & White & Heart & Egypt & Late \\
Giza 82 & Crawford x Maple presto & Purple & Heart & Egypt & Early \\
Giza 111 & Crawford x Celeste & Purple & Heart & Egypt & Late \\
\hline
\end{tabular}

Data from Food Legumes Research Department, Field Crops Research Institute, Agricultural Research Center, Egypt.

The experiment included fifteen treatments which were the combination between five intercropping patterns (alternating ridges; 1 maize : 3 soybean, 2 maize : 4 soybean, 2 maize : 2 soybean, 3 maize : 3 soybean and 4 maize : 2 soybean were expressed as $25 \%$ maize : $75 \%$ soybean, $33 \%$ maize : $67 \%$ soybean, $50 \%$ maize : $50 \%$ soybean, $50 \%$ maize : $50 \%$ soybean 'I' and $67 \%$ maize : $33 \%$ soybean, respectively) and three soybean cultivars (early - maturing cultivar Giza 82 and late - maturing cultivars; Giza 22 and Giza 111). The treatments were shown in Figure (1) as follows:

1. One maize ridge alternating with another three of soybean. This pattern resulted in 11900 and 285600 plants of maize and soybean/ha, respectively.

2. Two maize ridges alternating with another four of soybean. This pattern resulted in 15708 and 255136 plants of maize and soybean/ha, respectively.

3. Two maize ridges alternating with another two of soybean. This pattern resulted in 23800 and 190400 plants of maize and soybean/ha, respectively.

4. Three maize ridges alternating with another three of soybean. This pattern resulted in 23800 and 190400 plants of maize and soybean/ha, respectively.

5. Four maize ridges alternating with another two of soybean. This pattern resulted in 31892 and 125664 plants of maize and soybean/ha, respectively.

Maize was grown in one row/ridge by leaving one plant/hill spaced at $30 \mathrm{~cm}$, meanwhile soybean seeds were drilled in two rows/ridge and thinned to two plants /hill spaced at $15 \mathrm{~cm}$ ), in addition to:

1. Sole maize: pure stand of maize ridges by growing one plant/hill spaced at $30 \mathrm{~cm}$ (recommended pattern). This pattern resulted in 47600 maize plants/ha.

2. Sole soybean: pure stand of soybean ridges by drilling soybean seeds in two rows/ridge and soybean was thinned to two plants/hill spaced at $15 \mathrm{~cm}$ (recommended pattern). This pattern resulted in 380800 plants of soybean/ha.

Calcium super phosphate $\left(15.5 \% \quad \mathrm{P}_{2} \mathrm{O}_{5}\right)$ at rate of 357 $\mathrm{kg} / \mathrm{ha}$ and potassium sulfate $\left(48.0 \% \mathrm{~K}_{2} \mathrm{O}\right)$ at rate of $119 \mathrm{~kg} / \mathrm{ha}$ were applied during soil preparation for planting maize and soybean in the two summer seasons. Mineral N fertilizer of maize was applied at rate of 285.6 divided into two equal doses at 15 and 30 days from maize sowing.

Water was supplied by furrow irrigation. Seeds of soybean were inoculated with Bradyrhizobium japonicum and Arabic gum was used as a sticking agent. Soybean seeds were sown on May $13^{\text {th }}$ and $9^{\text {th }}$ in 2014 and 2015 seasons, 

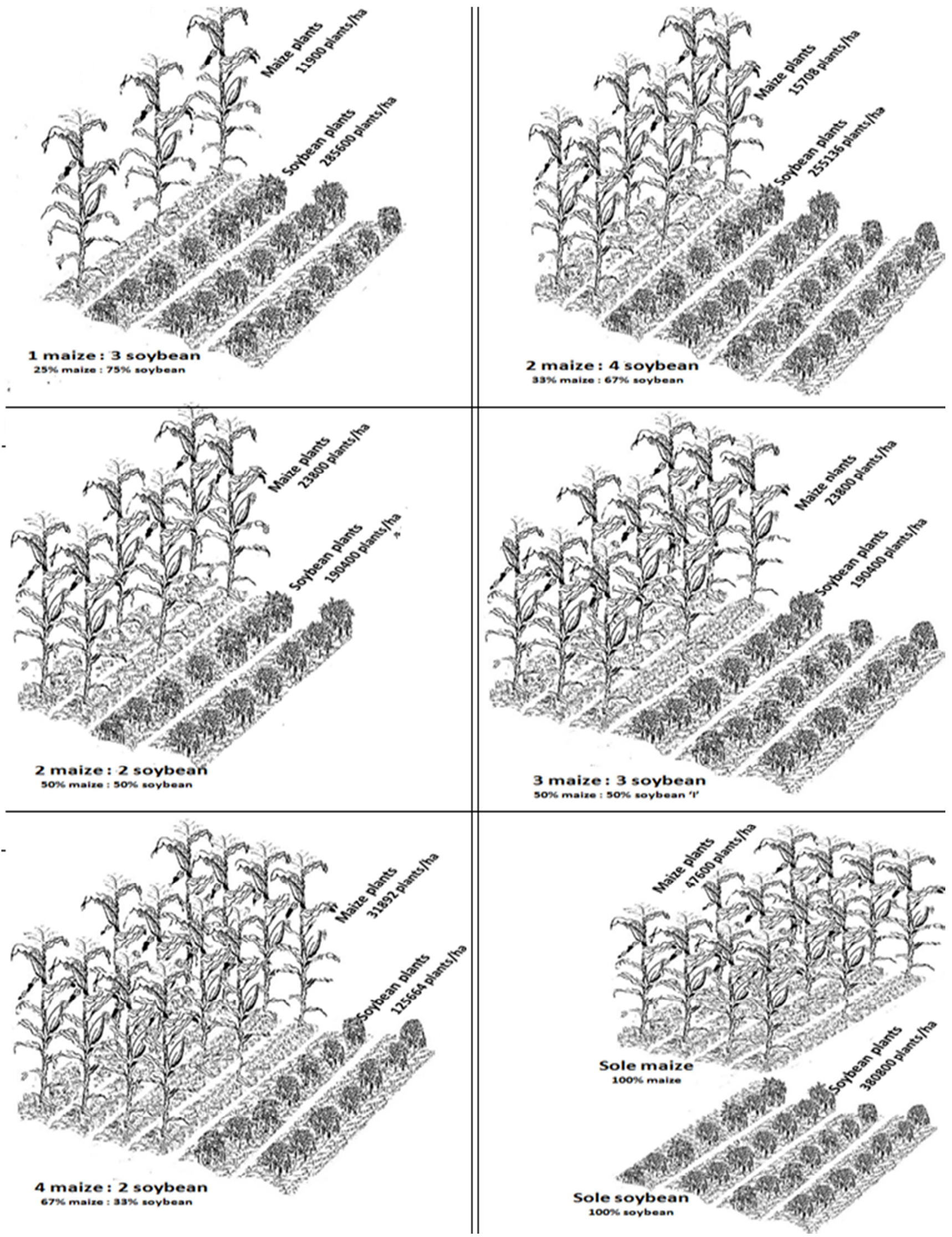

Figure 1. Intercropping soybean with maize under different patterns and sole cultures of both crops. 
respectively, meanwhile maize grains were sown on May $19^{\text {th }}$ and $15^{\text {th }}$ in 2014 and 2015 seasons, respectively. Soybean cultivar Giza 82 was harvested on August $18^{\text {th }}$ and $14^{\text {th }}$ in 2014 and 2015 seasons, respectively, meanwhile soybean cultivars Giza 22 and Giza 111 were harvested on September $15^{\text {th }}$ and $10^{\text {th }}$ in 2014 and 2015 seasons, respectively. Maize plants were harvested on September $18^{\text {th }}$ and $15^{\text {th }}$ in 2014 and 2015 seasons, respectively. The treatments were laid out in split plot design with three replications. Intercropping patterns were randomly assigned to the main plots and soybean cultivars were devoted to sub plots. The area of sub plot was $25.2 \mathrm{~m}^{2}$, each sub plot consisted of 12 ridges and each ridge was $3.0 \mathrm{~m}$ in length and $0.7 \mathrm{~m}$ in width.

\subsection{The Studied Traits}

\subsubsection{Maize Traits}

The following traits were measured on ten guarded plants from each sub plot at harvest; plant height $(\mathrm{cm})$ and, stem diameter $(\mathrm{cm})$, number of ears/plant, ear length $(\mathrm{cm})$, ear diameter $(\mathrm{cm})$, ear weight $(\mathrm{g})$ and grain yield per plant $(\mathrm{g})$. Grain yield/ha (ton) was recorded on the basis of experimental plot area by harvesting all plants of each sub plot.

\subsubsection{Soybean Traits}

Light intensity (lux) inside soybean canopy at middle and bottom of the plant was recorded by Lux-meter apparatus at mid - day on five plants from each sub plot at 75 days from soybean sowing and expressed as percentage from full sunlight intensity $(100 \%)$ measured above the plants. The following traits were measured on ten guarded soybean plants from each sub plot at harvest; plant height $(\mathrm{cm})$, numbers of branches and pods per plant, seed index $(\mathrm{g})$ and seed yield/plant (g). Biological and seed yields/ha (ton) were recorded on the basis of experimental sub plot area by harvesting all plants of each sub plot.

\subsubsection{Competitive Relationships}

\subsubsection{Land Equivalent Ratio (LER)}

LER defines as the ratio of area needed under sole cropping to one of intercropping at the same management level to produce an equivalent yield [15]. It is calculated as follows: $L E R=\left(Y_{a b} / Y_{a a}\right)+\left(Y_{b a} / Y_{b b}\right)$, where $Y_{a a}=$ Pure stand yield of crop a (maize), $Y_{b b}=$ Pure stand yield of crop $b$ (soybean), $\mathrm{Y}_{\mathrm{ab}}=$ Intercrop yield of crop a (maize) and $\mathrm{Y}_{\mathrm{ba}}=$ Intercrop yield of crop b (soybean).

\subsubsection{Area Time Equivalent Ratio (ATER)}

Area time equivalent ratio provides more realistic comparison of the yield advantage of intercropping over monocropping in terms of time taken by component crops in the intercropping systems. ATER was calculated by formula: ATER $=$ LER $\times D_{c} / D_{t}[16]$, Where LER is land equivalent ratio of crop, $D_{c}$ is time taken by crop, $D_{t}$ is time taken by whole system.

\subsubsection{Farmer's Benefit}

It was calculated by determining the total costs and net return of intercropping culture as compared to recommended sole culture of maize

1) Total return of intercropping cultures $=$ Price of maize yield + price of soybean yield (US\$). To calculate the total return, the average of maize and soybean prices presented by Bulletin of Statistical Cost Production and Net Return [1] was used.

2) Net return per ha $=$ Total return - (fixed costs of maize + variable costs of soybean according to intercropping pattern).

\subsection{Statistical Manipulation}

Analysis of variance of the obtained results of each season was performed. The homogeneity test was conducted of error mean squares and accordingly, the combined analysis of the two experimental seasons was carried out. The measured variables were analyzed by ANOVA using MSTATC statistical package [17]. Mean comparisons were done using least significant differences (L.S.D) method at $5 \%$ level of probability to compare differences between the means [18].

\section{Results and Discussion}

\subsection{Maize Traits}

\subsubsection{Intercropping Patterns}

Plant height, stem diameter, number of ears/plant, ear length, ear diameter, ear weight, grain yields per plant and per ha were affected significantly by intercropping patterns in the combined data across 2014 and 2015 seasons (Table 2). Intercropping pattern $67 \%$ maize : $33 \%$ soybean had the highest values $(P \leq 0.05)$ of plant height and grain yield per ha, meanwhile intercropping pattern $25 \%$ maize : $75 \%$ soybean produced the shortest plant with the highest values of stem diameter, number of ears/plants, ear length, ear diameter, ear weight and grain yield per plant as compared with the other intercropping patterns. These data may be due to maize plants of intercropping pattern $67 \%$ maize : $33 \%$ soybean suffered from mutual shading than those of the other intercropping patterns. Mutual shading is known to increase the proportion of invisible radiation, which has a specific elongating effect upon plants [18]. Consequently, there was more shading inside maize plants of intercropping pattern $67 \%$ maize : $33 \%$ soybean which formed more amounts of plant hormones and resulted in an increase of inter node elongation of maize plant that reflected negatively on stem diameter. The increased maize plant height of intercropping pattern $67 \%$ maize : $33 \%$ soybean was due to thick plant stand compared to the other patterns. Stem diameter is strongly influenced by environmental conditions during stem elongation [19]. Also, the results show that the ear length and diameter decreased with increase in maize plant density per unit area, probably due to variable plant competition. However, it is expected that all 
leaves of maize plants are not light saturated even at high maize plant density within intercropping pattern. Therefore, maize plant had high ability for acclimation by increasing number of maize plants per unit area to reach $67 \%$ of pure stand which contributed mainly in increase in grain yield/ha. These results are in accordance with those obtained by Konuskan [20] and Mobaser et al. [21] who reported that stem diameter were lower in higher plant densities as a consequence of inter plant competition.

\subsubsection{Soybean Cultivars}

Plant height, stem diameter, number of ears/plant, ear length, ear diameter, ear weight, grain yields per plant and per ha were not affected by soybean cultivars in the combined data across 2014 and 2015 seasons (Table 2). These data may be primarily attributed to the ability of maize plant to be grown successfully during growth and development. Consequently, all the investigated soybean cultivars exerted the same kind of depressant effects $(P>$ 0.05 ) on maize plant under intercropping culture. Only a small fraction of the genetic diversity available is currently used in soybean breeding worldwide, especially the genetic base of soybean in the U.S. and Canada is narrow [22]. Therefore, genetic variation of the Egyptian soybean cultivars does not have sufficient capacity to influence the growth and development of intercropped maize plant. Accordingly, yielding ability of maize plant was not affected by the soybean cultivars. These results are in harmony with those obtained by Metwally et al. [23] and Abdel-Galil et al. [24] who revealed that there was vegetative vigour of maize plants more than soybean cultivars.

Table 2. Effect of intercropping patterns, soybean varieties and their interaction on maize grain yield and its attributes, combined data across 2014 and 2015 seasons.

\begin{tabular}{|c|c|c|c|c|c|c|c|c|c|c|c|c|c|c|c|c|}
\hline \multirow{2}{*}{ Treatments } & \multicolumn{4}{|c|}{ Plant height (cm) } & \multicolumn{4}{|c|}{ Stem diameter $(\mathrm{cm})$} & \multicolumn{4}{|c|}{ Ears/plant (no.) } & \multicolumn{4}{|c|}{ Ear length (cm) } \\
\hline & G.22 & G.82 & G.111 & Mean & G.22 & G.82 & G.111 & Mean & G.22 & G.82 & G.111 & Mean & G.22 & G.82 & G.111 & Mean \\
\hline $25 \%$ maize: $75 \%$ soybean & 223.33 & 225.66 & 225.32 & 224.77 & 2.46 & 2.42 & 2.43 & 2.43 & 1.18 & 1.15 & 1.18 & 1.17 & 21.56 & 21.53 & 21.57 & 21.55 \\
\hline $33 \%$ maize: $67 \%$ soybean & 232.33 & 233.00 & 233.67 & 233.00 & 2.35 & 2.30 & 2.31 & 2.32 & 1.12 & 1.10 & 1.10 & 1.10 & 21.24 & 21.22 & 21.19 & 21.21 \\
\hline $50 \%$ maize: $50 \%$ soybean & 249.66 & 247.00 & 248.91 & 248.52 & 2.14 & 2.10 & 2.11 & 2.11 & 1.09 & 1.09 & 1.10 & 1.09 & 20.50 & 20.44 & 20.42 & 20.45 \\
\hline $50 \%$ maize: $50 \%$ soybean 'I' & 254.00 & 252.33 & 252.52 & 252.95 & 2.06 & 2.05 & 2.08 & 2.06 & 1.05 & 1.06 & 1.05 & 1.05 & 20.15 & 20.05 & 20.09 & 20.09 \\
\hline $67 \%$ maize: $33 \%$ soybean & 268.66 & 267.00 & 269.02 & 268.22 & 1.83 & 1.80 & 1.83 & 1.82 & 1.01 & 1.01 & 1.01 & 1.00 & 19.91 & 19.87 & 19.92 & 19.90 \\
\hline Mean & 245.59 & 244.99 & 245.88 & 245.48 & 2.16 & 2.13 & 2.15 & 2.14 & 1.08 & 1.07 & 1.08 & 1.07 & 20.67 & 20.62 & 20.63 & 20.64 \\
\hline \multicolumn{4}{|c|}{ L.S.D. 0.05 Intercropping patterns } & 8.17 & & & & 0.33 & & & & 0.16 & & & & 0.72 \\
\hline \multicolumn{4}{|l|}{ L.S.D. 0.05 Soybean cultivars } & N.S. & & & & N.S. & & & & N.S. & & & & N.S. \\
\hline \multicolumn{4}{|l|}{ L.S.D. 0.05 Interaction } & N.S. & & & & N.S. & & & & N.S. & & & & N.S. \\
\hline \multicolumn{4}{|l|}{ Sole maize } & 272.33 & & & & 1.75 & & & & 1.01 & & & & 19.85 \\
\hline
\end{tabular}

Table 2. Continued.

\begin{tabular}{|c|c|c|c|c|c|c|c|c|c|c|c|c|c|c|c|c|}
\hline \multirow{2}{*}{ Treatments } & \multicolumn{4}{|c|}{ Ear diameter (cm) } & \multicolumn{4}{|c|}{ Ear weight (g) } & \multicolumn{4}{|c|}{ Grain yield/plant (g) } & \multicolumn{4}{|c|}{ Grain yield/ha (ton) } \\
\hline & G.22 & G.82 & G.111 & Mean & G.22 & G.82 & G.111 & Mean & G.22 & G.82 & G.111 & Mean & G.22 & G.82 & G.111 & Mean \\
\hline $25 \%$ maize: $75 \%$ soybean & 5.33 & 5.24 & 5.32 & 5.29 & 273.66 & 275.23 & 273.42 & 274.10 & 216.38 & 220.54 & 219.69 & 218.87 & 2.53 & 2.52 & 2.53 & 2.52 \\
\hline $33 \%$ maize: $67 \%$ soybean & 5.10 & 5.05 & 5.06 & 5.07 & 271.49 & 273.33 & 272.01 & 272.27 & 208.61 & 216.77 & 214.13 & 213.17 & 3.26 & 3.30 & 3.29 & 3.28 \\
\hline $50 \%$ maize: $50 \%$ soybean & 4.88 & 4.80 & 4.89 & 4.85 & 230.18 & 228.17 & 228.83 & 229.06 & 196.56 & 195.01 & 196.24 & 195.93 & 4.62 & 4.61 & 4.55 & 4.59 \\
\hline $50 \%$ maize:50\% soybean 'I' & 4.60 & 4.56 & 4.56 & 4.57 & 205.46 & 207.06 & 207.49 & 206.67 & 195.20 & 196.84 & 195.46 & 195.83 & 4.56 & 4.63 & 4.49 & 4.56 \\
\hline $67 \%$ maize: $33 \%$ soybean & 4.50 & 4.45 & 4.51 & 4.48 & 185.14 & 182.78 & 184.32 & 184.08 & 184.43 & 181.03 & 183.30 & 182.92 & 5.64 & 5.73 & 5.60 & 5.65 \\
\hline Mean & 4.88 & 4.82 & 4.86 & 4.85 & 233.18 & 233.31 & 233.21 & 233.23 & 200.23 & 202.03 & 201.76 & 201.34 & 4.12 & 4.15 & 4.09 & 4.12 \\
\hline \multicolumn{4}{|c|}{ L.S.D. 0.05 Intercropping patterns } & 0.36 & & & & 86.99 & & & & 32.43 & & & & 1.73 \\
\hline \multicolumn{4}{|l|}{ L.S.D. 0.05 Soybean cultivars } & N.S. & & & & N.S. & & & & N.S. & & & & N.S. \\
\hline \multicolumn{4}{|l|}{ L.S.D. 0.05 Interaction } & N.S. & & & & N.S. & & & & N.S. & & & & N.S. \\
\hline \multicolumn{4}{|l|}{ Sole maize } & 4.39 & & & & 150.34 & & & & 148.40 & & & & 7.01 \\
\hline
\end{tabular}

\subsubsection{Response of Intercropping Patterns to Soybean Cultivars}

Plant height, stem diameter, number of ears/plant, ear length, ear diameter, ear weight, grain yields per plant and per ha were not affected by interaction between intercropping patterns and soybean cultivars in the combined data across
2014 and 2015 seasons (Table 2). These data show that each of these two factors act independently on all the studied traits of maize plant meaning that soybean cultivars responded similarly $(P>0.05)$ to intercropping patterns for the studied maize traits. These results are confirmed with those obtained by Metwally et al. [23] and Abdel-Galil et al. [24] who found that maize traits were not affected by cropping systems $\mathrm{x}$ 
soybean cultivars.

\subsection{Soybean Traits}

\subsubsection{Intercropping Patterns}

Intercepted light intensity within soybean canopy, biological yield per ha, plant height, numbers of branches and pods per plant, seed index, seed yields per plant and per ha were affected significantly by intercropping patterns in the combined data across 2014 and 2015 seasons (Table 3). Soybean plants of intercropping pattern $25 \%$ maize : $75 \%$ soybean had the highest values $(P \leq 0.05)$ of intercepted light intensity within soybean canopy, number of branches and pods per plant, seed index, seed yields per plant and per ha as compared to those of the other intercropping patterns. Conversely, soybean plants of intercropping pattern $25 \%$ maize : $75 \%$ soybean gave the shortest soybean plant as compared to those of the other intercropping patterns. This pattern could be decreased internode elongation of soybean plant as a result of decreasing plant hormones. There were differential responses achieved increases in light interception indirectly by decreasing plant density of the cereal component, thereby modifying light intensity intercepted by the canopy of the legume component under intercropping conditions. Clearly, percentage of light intensity at middle and bottom of soybean canopy was decreased gradually by increasing maize plant density from 25 to $67 \%$ of sole maize.

Table 3. Effect of intercropping patterns, soybean cultivars and their interaction on soybean seed yield and its attributes, combined data across 2014 and 2015 seasons.

\begin{tabular}{|c|c|c|c|c|c|c|c|c|c|c|c|c|}
\hline \multirow{3}{*}{ Treatments } & \multicolumn{8}{|c|}{ Percentage of light intensity (lux) at } & \multirow{2}{*}{\multicolumn{4}{|c|}{ Biological yield/ha (ton) }} \\
\hline & \multicolumn{4}{|c|}{ Middle of the canopy } & \multicolumn{4}{|c|}{ Bottom of the canopy } & & & & \\
\hline & G.22 & G.82 & G.111 & Mean & G.22 & G.82 & G.111 & Mean & G.22 & G.82 & G.111 & Mean \\
\hline $25 \%$ maize: $75 \%$ soybean & 9.94 & 9.82 & 9.38 & 9.71 & 5.28 & 5.17 & 4.91 & 5.12 & 10.54 & 10.35 & 11.06 & 10.65 \\
\hline $33 \%$ maize: $67 \%$ soybean & 9.77 & 9.68 & 9.20 & 9.55 & 5.13 & 5.01 & 4.78 & 4.97 & 9.48 & 9.24 & 9.35 & 9.35 \\
\hline $50 \%$ maize: $50 \%$ soybean & 9.24 & 9.10 & 8.83 & 9.05 & 4.69 & 4.60 & 4.16 & 4.48 & 7.21 & 7.17 & 7.64 & 7.34 \\
\hline $50 \%$ maize: $50 \%$ soybean 'I' & 9.16 & 9.03 & 8.78 & 8.99 & 4.61 & 4.47 & 4.09 & 4.39 & 6.83 & 6.58 & 7.54 & 6.98 \\
\hline $67 \%$ maize: $33 \%$ soybean & 8.62 & 8.54 & 8.11 & 8.42 & 4.37 & 4.25 & 3.92 & 4.18 & 4.72 & 4.58 & 5.26 & 4.85 \\
\hline Average of soybean cultivars & \multirow[t]{4}{*}{9.34} & \multirow[t]{4}{*}{9.23} & 8.86 & 9.14 & \multirow[t]{4}{*}{4.81} & \multirow[t]{4}{*}{4.70} & \multirow[t]{4}{*}{4.37} & 4.62 & \multirow[t]{4}{*}{7.75} & \multirow[t]{4}{*}{7.58} & \multirow[t]{4}{*}{8.17} & 7.83 \\
\hline L.S.D. 0.05 Cropping systems & & & & 0.87 & & & & 0.41 & & & & 0.43 \\
\hline L.S.D. 0.05 Soybean cultivars & & & & 0.44 & & & & 0.27 & & & & 0.32 \\
\hline L.S.D. 0.05 Interaction & & & & 1.16 & & & & 0.46 & & & & 0.54 \\
\hline Sole soybean & 10.71 & 10.63 & 10.26 & 10.53 & 5.52 & 5.43 & 5.18 & 5.37 & 13.92 & 13.73 & 14.00 & 13.88 \\
\hline \multirow{2}{*}{ Treatments } & \multicolumn{4}{|c|}{ Plant height (cm) } & \multicolumn{4}{|c|}{ Branches/plant (no.) } & \multicolumn{4}{|c|}{ Pods/plant (no.) } \\
\hline & G.22 & G.82 & G.111 & Mean & G.22 & G.82 & G.111 & Mean & G.22 & G.82 & G.111 & Mean \\
\hline $25 \%$ maize: $75 \%$ soybean & 93.47 & 89.80 & 99.17 & 94.14 & 3.42 & 3.22 & 3.83 & 3.49 & 37.94 & 35.21 & 36.04 & 36.39 \\
\hline $33 \%$ maize: $67 \%$ soybean & 94.58 & 90.62 & 101.02 & 95.40 & 3.18 & 3.01 & 3.67 & 3.28 & 37.64 & 34.72 & 35.56 & 35.97 \\
\hline $50 \%$ maize: $50 \%$ soybean & 97.15 & 92.68 & 104.53 & 98.12 & 2.91 & 2.77 & 3.58 & 3.08 & 37.22 & 34.11 & 35.41 & 35.58 \\
\hline $50 \%$ maize: $50 \%$ soybean 'I' & 97.65 & 92.82 & 105.11 & 98.52 & 2.91 & 2.72 & 3.49 & 3.04 & 37.07 & 34.01 & 35.32 & 35.46 \\
\hline $67 \%$ maize: $33 \%$ soybean & 103.71 & 96.33 & 111.29 & 103.77 & 2.68 & 2.44 & 3.11 & 2.74 & 36.77 & 33.83 & 35.02 & 35.20 \\
\hline Average of soybean cultivars & \multirow[t]{4}{*}{97.31} & \multirow[t]{4}{*}{92.45} & \multirow[t]{4}{*}{104.22} & 97.99 & \multirow[t]{4}{*}{3.02} & \multirow[t]{4}{*}{2.83} & \multirow[t]{4}{*}{3.53} & 3.12 & \multirow[t]{4}{*}{37.32} & 34.37 & 35.47 & 35.72 \\
\hline L.S.D. 0.05 Cropping systems & & & & 0.87 & & & & 0.41 & & & & 0.33 \\
\hline L.S.D. 0.05 Soybean cultivars & & & & 0.44 & & & & 0.27 & & & & 0.24 \\
\hline L.S.D. 0.05 Interaction & & & & 1.16 & & & & 0.46 & & & & 0.38 \\
\hline Sole soybean & 90.02 & 85.30 & 97.44 & 90.92 & 3.46 & 3.30 & 3.92 & 3.56 & 38.18 & 35.54 & 36.85 & 35.85 \\
\hline Treatments & Seed in & (g) & & & Seed & 1/plant & & & Seed y & eld/ha ( & on) & \\
\hline irea & G.22 & G.82 & G.111 & Mean & G.22 & G.82 & G.111 & Mean & G.22 & G.82 & G.111 & Mean \\
\hline $25 \%$ maize: $75 \%$ soybean & 12.99 & 12.63 & 11.16 & 12.26 & 8.61 & 8.29 & 7.72 & 8.20 & 2.55 & 2.36 & 2.29 & 2.40 \\
\hline $33 \%$ maize: $67 \%$ soybean & 12.62 & 12.39 & 10.74 & 11.91 & 8.35 & 8.01 & 7.55 & 7.97 & 2.19 & 2.01 & 1.94 & 2.04 \\
\hline $50 \%$ maize: $50 \%$ soybean & 12.19 & 11.88 & 10.21 & 11.42 & 8.12 & 7.78 & 7.39 & 7.76 & 1.58 & 1.54 & 1.35 & 1.49 \\
\hline $50 \%$ maize: $50 \%$ soybean 'I' & 11.74 & 11.31 & 10.03 & 11.02 & 8.01 & 7.62 & 7.35 & 7.66 & 1.48 & 1.49 & 1.31 & 1.42 \\
\hline $67 \%$ maize: $33 \%$ soybean & 11.29 & 9.96 & 9.77 & 10.34 & 7.87 & 7.48 & 7.28 & 7.54 & 0.98 & 1.04 & 0.87 & 0.96 \\
\hline Average of soybean cultivars & 12.16 & 11.63 & 10.40 & 11.39 & 8.19 & 7.83 & 7.45 & 7.82 & 1.75 & 1.68 & 1.55 & 1.66 \\
\hline L.S.D. 0.05 Cropping systems & & & & 0.34 & & & & 0.16 & & & & 0.12 \\
\hline L.S.D. 0.05 Soybean cultivars & & & & 0.25 & & & & 0.13 & & & & 0.07 \\
\hline L.S.D. 0.05 Interaction & & & & 0.41 & & & & 0.18 & & & & 0.18 \\
\hline Sole soybean & 13.11 & 12.82 & 11.36 & 12.43 & 8.70 & 8.42 & 7.92 & 8.34 & 3.30 & 3.22 & 3.01 & 3.17 \\
\hline
\end{tabular}

Accordingly, shading effects of intercropping pattern $67 \%$ maize : $33 \%$ soybean formed unfavorable conditions for soybean plant during the early stages of soybean growth and development, consequently more amounts of plant hormones. Moreover, as the soybean plant becomes taller, self-shading is enhanced and there may be an exceedingly steep light gradient between the top and bottom of the plant [25]. These results were reported by Undie et al. [26] who revealed that soybean plant height was increased above its sole crop height at all intercrop arrangements.

It is important to note that increasing maize plant density from 25 to $67 \%$ of sole maize increased shading intensity around soybean plants and consequently little dry matter accumulation of soybean plant. Obviously, pod number per plant as the yield component was most influenced by change in cultural and environmental conditions [27]. It is known that light enrichment and shading imposed during early flowering stage would change assimilates availability to the 
developing reproductive structures, influence flowering, and flower and pod abscission number with a resultant change in final pod number at harvest [13].

These results are in the same context of those obtained by Egbe [28] who showed that intercropped soybean produced lower seed yield than their sole crop counterparts. Also, Metwally et al. [29] showed that soybean solid plantings had the highest weight of 100 seeds, seed yields per plant and per ha as compared to those grown with maize under intercropping cultures. Moreover, Ijoyah et al. [30] showed that intercropping soybean with maize reduced $(P \leq 0.05)$ soybean yield by 43.8 and $55.6 \%$ in 2011 and 2012, respectively.

\subsubsection{Soybean Cultivars}

Soybean cultivars differed significantly for intercepted light intensity with soybean canopy, biological yield per ha, plant height, numbers of branches and pods/plant, seed index, seed yields per plant and per ha in the combined data across 2014 and 2015 seasons (Table 3). The late maturing soybean cultivar Giza 22 recorded the highest values $(P \leq 0.05)$ of intercepted light intensity within soybean canopy, number of branches/plant, number of pods/plant, seed index, seed yields per plant and per ha compared to the other soybean cultivars. Soybean cultivar Giza 22 or Giza 82 intercepted more light intensity at middle and bottom of the canopy than Giza 111 cultivar. Middle of soybean cultivars Giza 22 and Giza 82 canopies received 9.34 and $9.23 \%$ of full sunlight, respectively. Also, Giza 22 and Giza 82 intercepted 4.81 and $4.70 \%$ of full sunlight, respectively, at bottom of the plant. Obviously, the penetration of solar radiation to either the canopy of Giza 22 or Giza 82 cultivar was better than the other cultivar. However, soybean cultivar Giza 111 produced the highest biological yield per ha, plant height and number of branches per plant compared with the others.

Also, soybean cultivar Giza 111 gave the maximum plant height and number of branches per plant (104.22 $\mathrm{cm}$ and 3.53) followed by Giza $22(97.31 \mathrm{~cm}$ and 3.02) then Giza $82(92.45$ $\mathrm{cm}$ and 2.83), respectively. This result could be due to the longer vegetative growth period of the late maturity cultivars (Table 1). The two late soybean cultivars (Giza 22 and Giza 111) had greater growth and yield performance than the early Giza 82 cultivar because the late cultivars were able to utilize the environmental resources more than the early cultivar. However, soybean cultivar Giza 22 produced the highest number of pods/plant, seed index, seed yield per plant and per ha compared to the others. These results may be due to canopy structure of soybean cultivar Giza 22 had narrow leaves [29] that permitted more solar radiation to the other leaves of the plant and increased accumulation of dry matter in different organs of the plant which reflected on seed yield per plant as compared with the others. On the other hand, canopy structure of soybean cultivar Giza 111 had broad leaves [29] that decreased light penetration into the canopy and hence seed index and seed yield of this cultivar was not improved under the low light intensity condition as compared with the others. So, it may be possible that morphological traits of Giza 111 increased self-shading intensity compared with the others. Moreover, the difference in number of pods per plant can be attributed to differences in genetic makeup of the cultivars [31]. Obviously, soybean cultivar Giza 22 had high ability to overcome the severe conditions of intercropping culture as compared with the other cultivars [32].

Similar results were observed by Abd El-Mohsen et al. [31] who investigated that the lowest of number of branches and pods per plant was achieved in Giza 82 compared to the others. Also, Abdel-Galil et al. [32] indicated that Giza 111 had the lowest values of seed index and seed yields per plant and per ha.

\subsubsection{Response of Intercropping Patterns to Soybean Cultivars}

Intercepted light intensity within soybean canopy, biological yield per ha, plant height, numbers of branches and pods per plant, seed index, seed yields per plant and per ha were affected significantly by intercropping patterns $\mathrm{x}$ soybean cultivars in the combined data across 2014 and 2015 seasons (Table 3). Soybean cultivar Giza 22 of intercropping pattern $25 \%$ maize : $75 \%$ soybean recorded the highest values of intercepted light intensity within soybean canopy, number of pods per plant, seed index, seed yields per plant and per ha, meanwhile, soybean cultivar Giza 111 of the same pattern gave the highest values of biological yield per ha, plant height and number of branches per plant. Moreover, soybean cultivar Giza 82 ranked second cultivar with intercropping pattern $25 \%$ maize : $75 \%$ soybean for intercepted light intensity within soybean canopy, number of pods per plant, seed index, seed yields per plant and per ha. These results may be due to intercropping pattern $25 \%$ maize : 75\% soybean interacted positively with canopy structure of soybean cultivar Giza 22 which permit more solar radiation to the other leaves of this cultivar compared to the other treatments. These data reveal that there was significant effect $(P \leq 0.05)$ of the interaction between intercropping patterns and soybean cultivars on the studied soybean traits.

\subsection{Competitive Relationships}

\subsubsection{Land Equivalent Ratio (LER)}

The values of LER were estimated by using data of recommended solid cultures of both crops. Intercropping maize with soybean increased LER as compared to sole cultures of both crops in the combined data across 2014 and 2015 seasons (Figure 2). It ranged from 1.07 (by intercropping $67 \%$ of maize plants with $33 \%$ of soybean cultivar Giza 111) to 1.13 (by intercropping $25 \%$ of maize plants with $75 \%$ of soybean cultivar Giza 22 or by intercropping $67 \%$ of maize plants with $33 \%$ of soybean cultivar Giza 82) with an average of 1.09. LER was affected significantly by intercropping patterns in the combined data across 2014 and 2015 seasons. The advantage of the highest LER by intercropping soybean with maize over sole cultures could be due to minimize intra - specific competition 
between the two species for basic growth resources. Obviously, increasing maize plant density per unit area increased relative yield of maize and decreased relative yield of soybean. Consequently, LER depended on intercropping pattern. These results are in accordance with those obtained by Hayder et al. [33] who reported that the total relative yield of corn and soybean was greater in intercropping than monoculture. Also, Abdel-Galil et al. [32] found that intercropping culture increased LER as compared to sole cultures of both crops.

LER was affected significantly by soybean cultivars in the combined data across 2014 and 2015 seasons (Figure 2). Soybean cultivars Giza 22 and Giza 82 gave the highest LER, meanwhile the lowest LER was obtained by soybean cultivar Giza 111. It seems that relative yield of maize was constant under all the studied soybean cultivars. Accordingly, the fundamental reason to change the values of LER was relative yield of soybean cultivars. Clearly, the late-maturing cultivar Giza 22 had narrow leaves that increased intercepted light intensity during growth and development which reflected positively seed yield per plant. On the other hands, the earlymaturing cultivar Giza 82 was the shortest cultivar (Table 3) and completed its life cycle quickly. It worthy to mention that the late-maturing cultivar Giza 111 was the tallest cultivar (Table 3) with broad leaves that enhanced self-shading and consequently little dry matter accumulation which reflected negatively on the economic yield. These differences among the three cultivars were attributed to the fact that the cultivars were developed for growth in different climates. The latematuring cultivar Giza 22 or Giza 111 was developed for a warmer climate than the early-maturing cultivar Giza 82 and consequently shows an adaptation for low shading intensity.

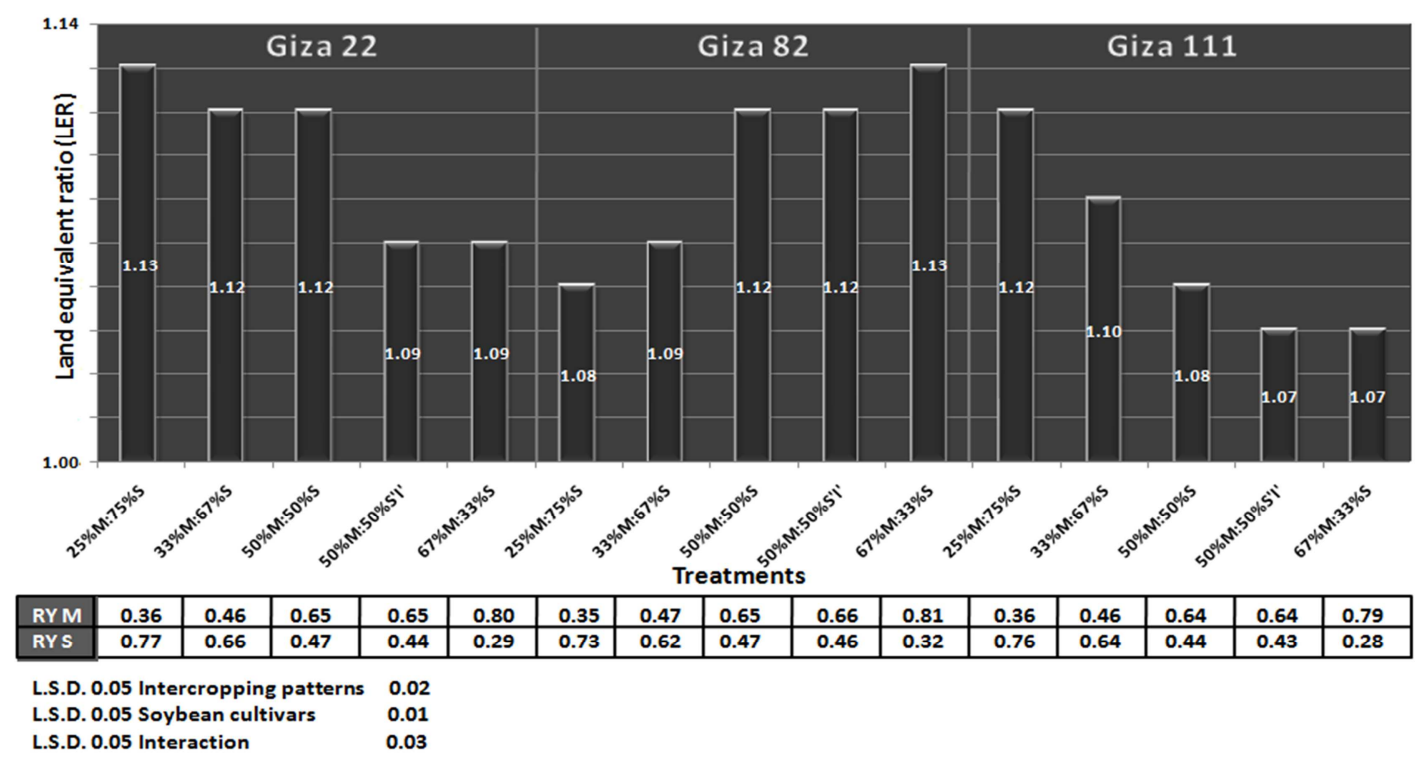

Figure 2. Relative yields of maize and soybean and land equivalent ratio (LER) as affected by intercropping patterns, soybean cultivars and their interaction, combined data across 2014 and 2015 seasons.

LER was affected negatively by the interaction between intercropping patterns and soybean cultivars in the combined data across 2014 and 2015 seasons (Figure 2). Relative yields of soybean cultivars Giza 22 and Giza 111 were increased by increasing number of soybean plants per unit area from 50 to $75 \%$ of sole culture with decreasing maize plant density from 50 to $25 \%$ of sole culture. Conversely, relative yield of soybean cultivar Giza 82 was increased by increasing number of maize plants per unit area from 50 to $67 \%$ of sole culture with decreasing soybean plant density from 50 to $33 \%$ of sole culture. These results show that the relative yields of three soybean cultivars could be related more to number of maize plants per unit area under intercropping conditions. Relative yield of soybean cultivar Giza 22 or Giza 111 was higher than the other cultivar under intercropping condition.

Soybean cultivar Giza 82 seems to be better adapted to increase in number of maize plants per unit area compared to the other cultivars (Figure 2). Seed yield reduction in Giza 82 cultivar due to shading effects of maize plants was lower than that of other cultivars. Therefore, it is likely that soybean cultivar Giza 82 was more adapted to low light intensity compared to the others under intercropping conditions. These results may be due to soybean cultivar Giza 82 had self regulation mechanism of redistributing the available assimilates to components, in an attempt to maintain or improve yield under low light intensity. One of these mechanisms of soybean cultivar Giza 82 was cross pollination of soybean cultivar Crawford and soybean cultivar Maple Presto (Table 1). It is known that soybean cultivar Maple Presto was intended to provide an agronomically suitable cultivar for production in areas of Canada with short and cool growing seasons [34].

The other mechanism of soybean cultivar Giza 82 was due to this cultivar was earlier matured than Giza 22 or Giza 111 cultivar. In this concern, Gourdon and Planchon [35] showed that Maple Presto cultivar has a shorter vegetative growth phase and a substantially shorter reproductive phase, shading on seeds yield per area depends on duration of shading [36]. 
This implies that single plant nutrient area of three soybean cultivars is different and is also helpful for making decision on optimum density of both crops under intercropping culture. These results are in parallel with those obtained by Metwally et al. [37] who indicated that good yielding ability of soybean cultivar Giza 82 under intercropping culture may be due to least effect of intercropping on individual plant characters. They added that soybean cultivar Giza 82 may be more adapted to low light intensity.

\subsubsection{Area Time Equivalent Ratio (ATER)}

ATER provides more realistic comparison of the yield advantage of intercropping over sole cropping in terms of variation in time taken by the component crops of different intercropping systems. Total ATER values of was more than one in all treatments except growing the early soybean cultivar Giza 82 in intercropping patterns $25 \%$ maize : $75 \%$ soybean, $33 \%$ maize : $67 \%$ soybean, 50\% maize : 50\% soybean and $50 \%$ maize : $50 \%$ soybean 'I' in the combined data across 2014 and 2015 seasons (Figure 3). In all the treatments, the ATER values were lesser than LER values (Figure 2) indicating the over estimation of resource utilization.

ATER was affected significantly by intercropping patterns in the combined data across 2014 and 2015 seasons (Figure 3). The advantage of the highest ATER by intercropping soybean with maize over sole cultures could be due to minimize intra - specific competition between plants of each crop for basic growth resources indicating higher productivity per unit area.

ATER was affected significantly by soybean cultivars in the combined data across 2014 and 2015 seasons (Figure 3).
Soybean cultivars Giza 22 and Giza 111 had the highest ATER, meanwhile the lowest ATER was obtained by soybean cultivar Giza 82. Clearly, growth duration of Giza 22 and Giza 111 was longer than that of Giza 82 which reflected positively on ATER values.

ATER was affected significantly by the interaction between intercropping patterns and soybean cultivars in the combined data across 2014 and 2015 seasons (Figure 3). Soybean cultivars Giza 22 and Giza 111 of intercropping pattern 25\% maize : $75 \%$ soybean had the highest values of ATER, meanwhile Giza 82 cultivar of intercropping $67 \%$ maize : $33 \%$ soybean recorded the highest ATER compared to the other treatments. These results could be due to relative yields of soybean cultivars Giza 22 and Giza 111 were increased by increasing soybean plant density from 50 to $75 \%$ of sole culture with decreasing number of maize plants per unit area from 50 to $25 \%$ of sole culture. Conversely, relative yield of soybean cultivar Giza 82 was increased by increasing maize plant density from 50 to $67 \%$ of sole culture with decreasing number of soybean plants per unit area from 50 to $33 \%$ of sole culture. These results may be due to soybean cultivar Giza 82 had self regulation mechanism of redistributing the available assimilates to components, in an attempt to maintain or improve yield under high shading intensity.

\subsection{Farmer's Benefit}

Intercropping culture increased net return by $37.16 \%$ compared with sole maize (Table 4). The results indicate that intercropping soybean with maize was more profitable to farmers than sole maize under all

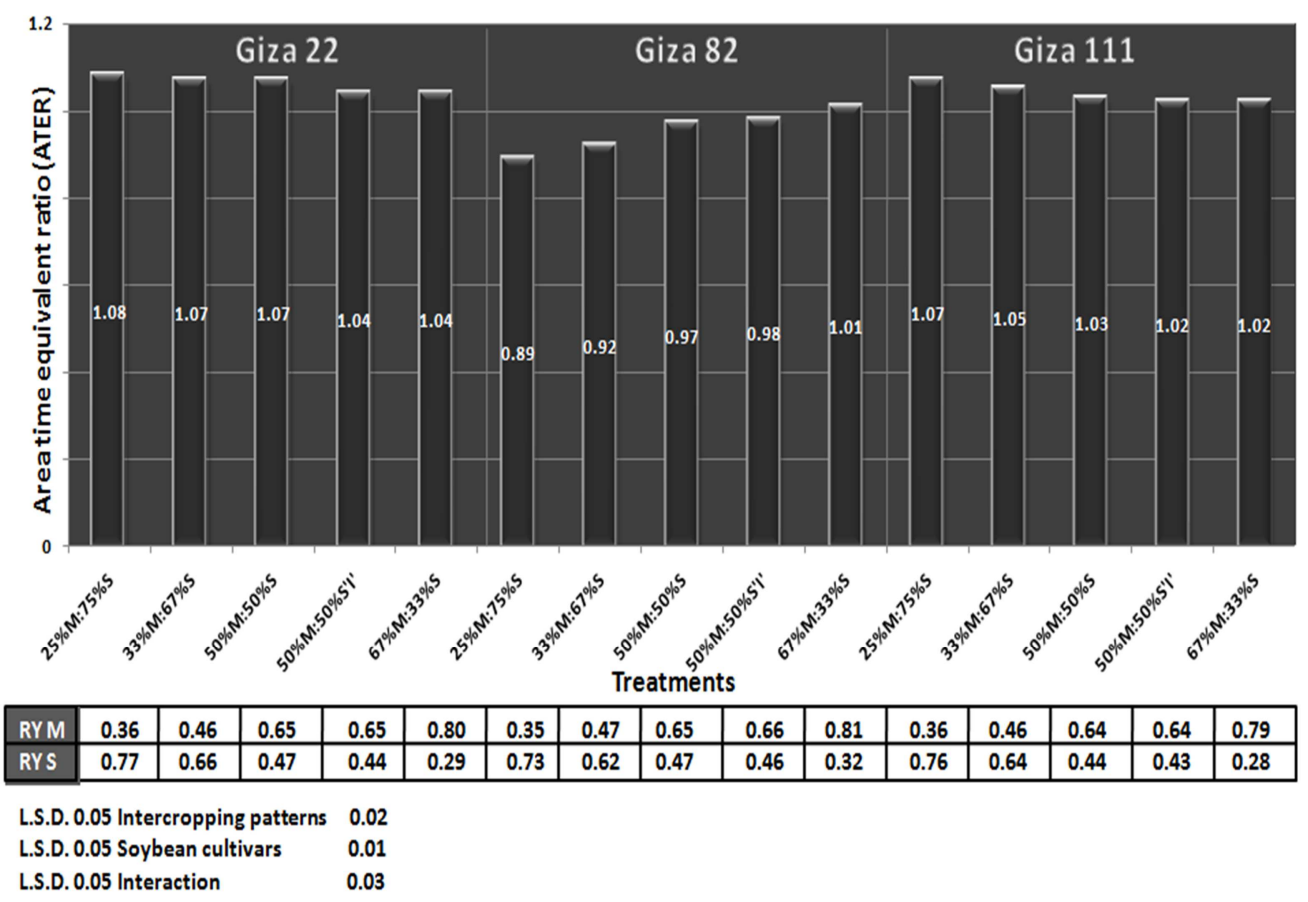

Figure 3. Area time equivalent ratio (ATER) as affected by intercropping patterns, soybean cultivars and their interaction, combined data across 2014 and 2015 seasons. 
intercropping patterns. Net return of intercropping soybean with maize was varied between treatments from US\$ 655 to 858 per ha compared with sole maize (US\$ 557 per ha). Soybean cultivar Giza 22 of intercropping patterns 50\% maize : $50 \%$ soybean had the highest net return (US\$ 858 per ha) followed by soybean cultivar Giza 82 of intercropping pattern 4 maize : 2 soybean (US\$ 847 per ha). These findings are parallel with those obtained by Metwally et al. [23], AbdelGalil et al. [32] and Lamlom et al. [38] who reported that intercropping system gave higher net return over sole maize.

Table 4. Total and net returns as affected by intercropping patterns, soybean cultivars and their interaction, combined data across 2014 and 2015 seasons.

\begin{tabular}{|c|c|c|c|c|c|c|c|c|c|c|c|c|c|c|c|c|}
\hline \multirow{2}{*}{ Treatments } & \multicolumn{4}{|c|}{ Soybean } & \multicolumn{4}{|c|}{ Maize } & \multicolumn{4}{|c|}{ Total } & \multicolumn{4}{|c|}{ Net } \\
\hline & G.22 & G.82 & G.111 & Mean & G.22 & G.82 & G.111 & Mean & G.22 & G.82 & G.111 & Mean & G.22 & G.82 & G.111 & Mean \\
\hline $25 \%$ maize: $75 \%$ soybean & 1532 & 1418 & 1376 & 1442 & 782 & 778 & 782 & 780 & 2314 & 2196 & 2158 & 2222 & 841 & 723 & 685 & 749 \\
\hline $33 \%$ maize: $67 \%$ soybean & 1316 & 1208 & 1165 & 1229 & 1007 & 1020 & 1016 & 1014 & 2323 & 2228 & 2181 & 2244 & 835 & 740 & 693 & 756 \\
\hline $50 \%$ maize: $50 \%$ soybean & 949 & 925 & 811 & 895 & 1428 & 1424 & 1406 & 1419 & 2377 & 2349 & 2217 & 2314 & 858 & 830 & 698 & 795 \\
\hline $50 \%$ maize: $50 \%$ soybean 'I' & 889 & 895 & 787 & 857 & 1409 & 1431 & 1387 & 1409 & 2298 & 2326 & 2174 & 2266 & 779 & 807 & 655 & 747 \\
\hline $67 \%$ maize: $33 \%$ soybean & 588 & 625 & 522 & 578 & 1743 & 1771 & 1730 & 1748 & 2331 & 2396 & 2252 & 2326 & 782 & 847 & 703 & 777 \\
\hline Mean & 1054 & 1014 & 932 & 1000 & 1273 & 1284 & 1264 & 1274 & 2328 & 2299 & 2196 & 2274 & 819 & 789 & 686 & 764 \\
\hline
\end{tabular}

Prices of main products are that of 2013: US\$ 601.0 for ton of soybean; US\$ 309.1 for ton of maize; intercropping soybean with maize increased variable costs of intercropping culture from US\$190 - 238 per ha over those of sole maize.

\section{Conclusion}

Our results concluded that the availability of low light intensity due to shading effect of maize was the critical factor in determining intercropped soybean cultivar. Relative yield could be beneficial for estimating the shade tolerance of soybean germplasm and choosing the special soybean cultivars for the intercropping. Giza 82 was the compatible soybean cultivar with increasing maize plant density from 50 to $67 \%$ of sole maize. Conversely, Giza 22 was the compatible soybean cultivar with increasing maize plant density from 25 to $50 \%$ of sole maize.

\section{References}

[1] Bulletin of Statistical Cost Production and Net Return. 2014. Summer and Nili Field Crops and Vegetables and Fruit, Agriculture Statistics and Economic Sector, Ministry of Egyptian Agriculture and Land Reclamation, Part (2), August 2014.

[2] Sayed Galal Jr and Metwally AA. 1982. The variability in intercropping tolerance of 18 soybean varieties when grown with a newly developed maize stock. Res. Bull., Ain Shams Univ., Cairo, 2101: 1- 15.

[3] Shafshak SE, Shokr El-S, Seif SAA and Shafie H. 1984. Intercropping maize and soybean as affected by various nitrogen levels. 2- Yield and yield components. Agric. Res. Rev. Abst., 62 (7): 78 p.

[4] El-Habbak KED. 1985. Studies on competition and intercropping in maize and soybean. Ph.D. Thesis, Fac. Agric. Moshtohor, Zagazig Univ.

[5] Sayed Galal Jr and Metwally AA. 1986. Science in practice. In: Proc. $2^{\text {nd }}$ Conf. Agron., Alexandria Univ., 1: 489-503, Egypt.

[6] El-Douby KA, El-Habbak KED, Khalil HE and Attia Zahira M. 1996. Effect of some intercropping patterns on growth and yield of maize and soybean. Ann. Agric. Sci., Moshtohor, 34 (3): 919 - 933, Egypt.
[7] Weil RR and McFadden ME. 1991. Fertility and weed stress effects on performance of maize/soybean intercrop. Agron. J., 83: 717-721.

[8] Liu XB, Jin J, Wang GH, Herbert S.J. 2008. Soybean yield physiology and development of high-yielding practices in Northeast China. Field Crops Res., 105: 157-171.

[9] Aynehband A, Behrooz M and Afshar AH. 2010. Study of intercropping agroecosystem productivity influenced by different crops and planting ratios. American-Eurasian J. Agric. and Environ. Sci., 7 (2): 163 - 169.

[10] Sayed Galal Jr, Abdalla MMF and Metwally AA. 1983. Intensifying land and nutrient equivalent ratios by intercropping corn and soybean in Egypt. Soybean in tropical and subtropical cropping systems. In: Proc. Symposium, Tsukubo, Japan, pp. $101-106$.

[11] Abdel-Galil AM, Abdel-Wahab ShI and Abdel-Wahab TI. 2014a. Compatibility of some maize and soybean varieties for intercropping under sandy soil conditions. Proc. 1stConf. of Int. Soybean Res., Indore, 22 - 24 February, India.

[12] Kakiuchi J and Kobata T. 2004. Shading and thinning effects on seed and shoot dry matter increase in determinate soybean during the seed-filling period. Agron. J., 96: 398 - 405.

[13] Liu B, Liu XB, Wang C, Li YS, Jin J and Herbert SJ. 2010. Soybean yield and yield component distribution acrossthe main axis in response to light enrichment and shading under different densities. Plant Soil Environ., 56 (8): 384-392.

[14] Mead R and Willey RW. 1980. The concept of a "land equivalent ratio" and advantages in yields from intercropping. Exp. Agric., 16: 217 - 28.

[15] Hiebsch CK. 1980. Principles of Intercropping. "Effect of N fertilization and crop duration on equivalency ratios in intercrops versus monoculture comparisons." $\mathrm{PhD}$ Thesis. North Carolina State University, Raleigh, N. C., USA.

[16] Freed RD. 1991. MSTATC Microcomputer Statistical Program. Michigan State University, East Lansing, Michigan, USA. 
[17] Gomez KA and Gomez AA. 1984. Statistical Procedures for Agricultural Research. $2^{\text {nd }}$ ed., John Willey and Sons, Toronto, ON, Canada.

[18] Chang JH. 1974. Radiation balance. Climatic and Agriculture. An ecological survey, pp. 4 - 22. Aldine Publishing Company, Chicago, Illinois, USA.

[19] Sharifi RS, Sedghi M and Gholipouri A. 2009. Effect of Population Density on Yield and Yield Attributes of Maize Hybrids. Res. J. Biological Sci., 4 (4): 375 - 379.

[20] Konuskan O. 2000. Effects of plant density on yield and yield related characters of some maize hybrids grown in hatay conditions as $2^{\text {nd }}$ crop. M.Sc. Thesis, Sci. Inst. M.K.U., 71p.

[21] Mobaser HR, Delarestaghi Khorgami MM, Tari A and Pourkalhor DB. 2007. Effect of planting density on agronomical characteristics of rice (Oryza sativa) varieties in North of Iran. Pak J. Biol. Sci., 10 (18): 3205 - 3209.

[22] Burton JW, Carter TE and Bowman DT. 2005. Registration of 'NC-Roy' soybean. Crop Sci., 45: 2654.

[23] Metwally AA, Shafik MM, El-Habbak KE and Abdel-Wahab ShI. 2009. Step forward for increasing intercropped soybean yield with maize. The 4th Conference, Recent Technologies in Agriculture, 3-5 Nov., Cairo Univ., 2: 256-269, Egypt.

[24] Abdel-Galil AM, Abdel-Wahab TI and Abdel-Wahab ShI. 2014b. Maize productivity under intercropping with four soybean varieties and maize planting geometry. Middle East J. Agric. Res., 3 (2): $346-352$.

[25] Addo-Quaye AA, Darkwa AA and Ocloo GK. 2011. Growth analysis of component crop in a maize-soybean intercropping system as affected by time of planting and spatial arrangement. ARPN J. Agric. and Biological Sci., 6 (6):34 - 44.

[26] Undie UL, Uwah DF and Attoe EE. 2012. Growth and development of late season maize/soybean intercropping in response to nitrogen and crop arrangement in the forest agroecology of South Southern Nigeria. Int. J. Agric. Res., 7(1): 1.

[27] Board JE. and Harville BG. 1992. Explanations for greater light interception in narrow- vs. wide-row soybean. Crop Sci., 32: $198-202$.
[28] Egbe OM. 2010. Effects of plant density of intercropped soybean with tall sorghum on competitive ability of soybean and economic yield at Otobi, Benue State, Nigeria. J. Cereals and Oilseeds 1(1): 1-10.

[29] Metwally AA, Shafik MM, El-Habbak KE and Abdel-Wahab ShI. 2012. Yield and soybean characters under some intercropping patterns with corn. Soybean Res., 10: 24- 42

[30] Ijoyah MO, Ogar AO and Ojo GOS. 2013. Soybean-maize intercropping on yield and system productivity in Makurdi, Central Nigeria. Scientific J. Crop Sci., 2 (4): 49 - 55.

[31] Abd El-Mohsen AA, Mahmoud Gamalat O and Safina SA. 2013. Agronomical evaluation of six soybean cultivars using correlation and regression analysis under different irrigation regime conditions. J. Plant Breed. Crop Sci., 5 (5): 91 - 102.

[32] Abdel-Galil AM, Abdel-Wahab TI and Abdel-Wahab ShI. 2014c. Productivity of four soybean varieties as affected by intercropping and corn planting geometry. Soybean Res., 12 (1): $36-58$.

[33] Hayder G, Mumtaz SS, Khan A and Khan S. 2003. Corn and soybean intercropping under various levels of soybean seed rates. Asian J. Plant Sci., 2: 339 - 241.

[34] Voldeng HD, Seitzer JF and Donovan LS.1982. Maple presto soybeans. Can. J. Plant Sci., 62: $501-503$.

[35] Gourdon F and P1anchon C. 1982. Responses of photosynthesis to irradiance and temperature in soybean, Glycine max. Photosynthesis Res., 3: 31 - 42.

[36] Jiang H and Egli DB. 1993. Shade induced changes in flower and pod number and flower and fruit abscission in soybean. Agron. J., 85: 221 - 225

[37] Metwally AA, Shafik MM; El-Metwally El-MA and Safina SA. 2003. Tolerance of some soybean varieties to intercropping. Proc. $10^{\text {th }}$ Conf. Agron., Suez Canal Univ., Fac. Environ. Sci., EL-Arish, Egypt. P.: 279 - 293.

[38] Lamlom MM, Abdel-Wahab ShI, Abdel-WahabTI and Gendy EK. 2015. Residual effects of some preceded winter field crops on productivity of intercropped soybean with three maize cultivars. American J. BioSci., 3(6): 226 - 242. 